\title{
ENSINO DE MATEMÁTICA PARA NORMALISTAS DO INSTITUTO DE EDUCAÇÃO RÉGIS PACHECO (1969-1972)
}

\author{
Cleide Selma Pereira dos Santos ${ }^{1}$ \\ Janice Cassia Lando²
}

\begin{abstract}
RESUMO: Neste artigo interpreta-se de que forma saberes relacionados ao ensino de matemática, contidos em um manual para professores primários, estiveram presentes na formação de normalistas do Instituto de Educação Régis Pacheco, em Jequié-BA, no período de 1969 a 1972. O recorte temporal se refere ao tempo de formação de duas depoentes e a data de publicação do manual $O$ livro didático: sua utilização em classe. O trabalho se fundamenta na História Cultural, no conceito de apropriação, conforme Chartier (2002); na História das Disciplinas Escolares, segundo Chervel (1990); e, para a produção dos depoimentos, na História Oral Temática, de acordo com Meihy (1996). Foi possível interpretar que os saberes a ensinar e os saberes para ensinar a matemática, abordados no citado curso e no manual analisados, davam enfoque, respectivamente, a conteúdos do primário e a modos de ensiná-los, com indícios da Escola Nova e do Movimento da Matemática Moderna.
\end{abstract}

Palavras-chave: Manual do professor. Curso Normal. Ensino de Matemática.

\section{MATHEMATICS TEACHING FOR NORMALISTS FROM INSTITUTO DE EDUCAÇÃO RÉGIS PACHECO (1969-1972)}

\begin{abstract}
In this article, we interpret the way in which knowledge related to mathematics teaching contained in a manual for primary teachers were present in formation of normalistas of Institute of Education Régis Pacheco, in Jequié-BA, from 1969 to 1972 .The temporal cut refers to formation time of two deponents and the date of publication of the manual O livro didático: sua utlização em classe. The work is based on Cultural History, on the concept of appropriation, according to Chartier (2002); in History of School Disciplines, according to Chervel (1990); and, for the production of testimonies, in Oral Thematic History, according to Meihy (1996). It was possible to interpret that the knowledge to teach and the knowledge for teaching mathematics - approached in the aforementioned course and in the analyzed manual - focused on the contents of elementary school and the ways of teaching them, respectively, with indications of Escola Nova and Movimento da Matemática Moderna.
\end{abstract}

\footnotetext{
${ }^{1}$ Mestre em Educação Científica e Formação de Professores. Docente do Instituto Federal de Educação, Ciência e Tecnologia Baiano. Jequie - BA/Brasil. E-mail. cleideselma10@hotmail.com

2 Doutorado em Ensino, Filosofia e História das Ciências. Docente da Universidade Estadual do Sudoeste da Bahia. Jequie BA/Brasil. E-mail: janicelando@gmail.com
} 
Keywords: Teacher's Manual. Normal Course. Mathematics Teaching.

\section{ENSEÑANZA DE MATEMÁTICA PARA NORMALISTAS DEL INSTITUTO DE EDUCAÇÃO RÉGIS PACHECO (1969-1972)}

RESUMEN: En este artículo se interpreta de qué forma los saberes relacionados a la enseñanza de matemática, contenidos en un manual para profesores primarios, estuvieron presentes en la formación de normalistas del Instituto de Educação Régis Pacheco, en Jequié, Bahia, Brasil, en el período de 1969 a 1972. El momento temporal se refiere al tiempo de formación de dos deponentes y la fecha de publicación del manual $O$ livro didático: sua utilização em classe. El trabajo se fundamenta en la Historia Cultural, en el concepto de apropiación, conforme Chartier (2002); en la Historia de las Disciplinas Escolares, según Chervel (1990); y, para la producción de las deposiciones, en la Historia Oral Temática, de acuerdo con Meihy (1996). Nos fue posible interpretar que los saberes a enseñar y los saberes para enseñar la matemática, abordados en el curso citado y en el manual analizado, enfocaban contenidos del primario y los modos de enseñarlos, respectivamente, con indicios de la Escola Nova y del Movimiento de la Matemática Moderna.

Palabras clave: Manual del profesor. Curso Normal. Enseñanza de Matemática.

Ao rememorarmos a história da formação docente no Brasil, presenciamos uma preocupação com a criação de Escolas Normais, em decorrência da constatação da necessidade de institucionalizar a formação de professores primários, já que faltavam professores qualificados para o ensino nesse nível de escolaridade e o ensino primário passou a ser visto como indispensável para o País, que buscava se desenvolver, como nação, após a proclamação da independência, em 1822 (TANURI, 2000). Na Bahia, a primeira Escola Normal foi fundada em 1836, mas foi a partir de 1920 - década marcada por um grande investimento em escolas primárias e por grande preocupação com relação à qualidade de ensino nelas ofertada - que houve um crescimento significativo de Escolas Normais neste estado (SOUZA; CRUZ, 2012).

A preocupação com a formação docente levou alguns estudiosos a escreverem livros destinados a orientar os professores sobre o que e como ensinar. No Instituto de Educação Régis Pacheco (IERP), encontramos vários livros com essa perspectiva. Assim, neste trabalho, buscamos interpretar de que forma saberes relacionados ao ensino de matemática, contidos em um manual destinado à formação de professores primários, estiveram presentes na 
formação de normalistas do Curso Normal do Instituto de Educação Régis Pacheco, localizado em Jequié-BA.

O manual utilizado para análise, intitulado O livro didático: sua utilização em classe, publicado pela Comissão do Livro Técnico e do Livro Didático (COLTED), foi escolhido por vários motivos. Primeiro por tratar uma temática relevante naquele período, uma vez que, "entre os anos 1950 e 1960 as discussões sobre o problema do livro didático integravam o ambiente de debates sobre a necessidade de reformulação da educação nacional [...]" (FILGUEIRAS, 2011 apud FILGUEIRAS, 2015, p. 88).

Isso se deu também porque uma discente do IERP, que havia estudado no Curso Normal da citada instituição no início da década de 1970, reconheceu esse manual como tendo sido utilizado por ela e suas colegas de turma. E ainda pelo fato de ele ter sido estruturado e publicado como um material para subsidiar os cursos de treinamento de professores promovidos pela Colted, com o objetivo "a curto prazo, de melhorar o rendimento didático e pedagógico das aulas ministradas, proporcionando um índice maior de aprendizagem e, a longo prazo, transformar as concepções do professor e do aluno com relação ao livro didático" (BATISTA; SANTOS; SOUZA, 2016, p. 1028). Dessa forma, essas fontes nos levam a inferir que tal manual, para além de ser um material dos cursos de treinamento, foi também utilizado em um curso de formação inicial de professores primários.

Realizamos uma pesquisa em 2016 e 2017, com o intuito de compreender como ocorreu a formação matemática dos estudantes do Curso Normal do Instituto de Educação Régis Pacheco (IERP), localizado em Jequié-BA, no período compreendido entre 1959 e 1971, datas que se referem, respectivamente, ao ano em que foi fundado o citado curso e em que foi promulgada a lei que transformou o Curso Normal em Magistério. Essa pesquisa resultou na escrita da dissertação de mestrado intitulada História da formação docente no Curso Normal do Instituto de Educação Régis Pacheco (1959-1971): o ensino da matemática em foco. A referida dissertação apresenta a interpretação de que o ensino de matemática do mencionado curso se consolidou a partir de duas perspectivas: a promoção de uma formação moral, cívica e religiosa, de acordo com os ideais propostos para o professor primário na época, a qual tinha uma relação com os objetivos propostos para o ensino da matemática; e pela apropriação e institucionalização de saberes - saberes a ensinar matemática e para 
ensinar matemática - oriundos tanto das disciplinas de formação geral como das disciplinas de formação profissional.

Os saberes a ensinar e saberes para ensinar, segundo Rita Hofstetter e Bernard Schneuwly (2017a) afirmam - com base em estudos realizados pela Equipe de Pesquisa em História das Ciências da Educação (ERHISE), da Universidade de Genebra, na Suíça - são aqueles institucionalizados para a profissão. Também, nas Escolas Normais é dado enfoque tanto aos saberes a ensinar, os quais se referem a conteúdos peculiares das disciplinas quanto aos saberes para ensinar, que aludem a conhecimentos oriundos do campo da educação que visam orientar o processo de ensino e aprendizagem das disciplinas, ou seja, saberes voltados à formação específica para o ensino.

Considerando os questionamentos que surgiram em decorrência da pesquisa relatada, dentre os quais está: o que abordavam os livros e os manuais encontrados na instituição, com relação aos saberes a ensinar e saberes para ensinar a matemática?, neste artigo pretendemos interpretar como as orientações contidas no manual intitulado O livro didático: sua utilização em classe, publicado em 1970, em sua segunda edição, pela Comissão do Livro Técnico e do Livro Didático (COLTED), encontrado no IERP, estiveram presentes na formação de normalistas da citada instituição, no final da década de 1960 e início da década de 1970 . O recorte temporal foi definido levando em conta a data de publicação do referido manual e o período em que duas discentes, cujos depoimentos utilizamos como fontes, estudaram no IERP - Jacy Andrade Sturken, de 1969 a 1971; e Nina Rosa Braga Cardoso, de 1970 a 1972.

O presente estudo se fundamenta na concepção de História Cultural, adotada por Chartier (2002), o qual afirma que as representações se constroem a partir das classificações e das exclusões que constituem, na sua diferença radical, as configurações sociais e conceptuais próprias de um tempo ou de um espaço. As estruturas sociais não são dadas, elas são produzidas pelas práticas culturais e sociais que, de forma articulada, demarcam e modelam as estruturas, dando origem às representações. $O$ autor também pontua que as práticas de apropriação cultural se configuram como formas diferenciadas de interpretação.

Também fomos buscar, como aporte teórico, a concepção de História das Disciplinas Escolares, de André Chervel (1990), o qual afirma que as disciplinas escolares são organizadas a partir dos consensos abstraídos de discussões em torno dos métodos e dos conteúdos 
adotados. Sendo assim, o estudo delas deve despender um esforço em interpretar tanto a história de seus conteúdos e métodos utilizados, bem como as finalidades a que se propõem e os resultados produzidos.

Valemo-nos ainda da História Oral Temática, de acordo com Meihy (1996), numa perspectiva histórica, a qual é utilizada, na maioria das vezes, de forma articulada com outros documentos, neste caso, com o manual da Colted. O roteiro de perguntas que norteou a entrevista teve como objetivo conhecer a formação dos professores, os conteúdos abordados no ensino da matemática no Curso Normal do IERP, as orientações teóricas e metodológicas abordadas no curso, os momentos de estágio, entre outras questões.

Para a produção deste artigo, escolhemos dentre o total de depoimentos produzidos como fontes na dissertação de mestrado dois deles, pois, conforme mencionamos anteriormente, as duas discentes estudaram no referido curso em tempo que coincide com o recorte temporal aqui adotado. As entrevistas foram realizadas com o uso de gravador, no intuito de dar maior precisão no momento da transcrição das histórias relatadas. Após a transcrição dos depoimentos, as discentes fizeram a leitura atenta deles, revisaram e aprovaram o texto. Além de depoimento oral, ambas as estudantes escreveram de próprio punho depoimentos complementares.

Quanto à análise do manual para professores primários, esta privilegiou os princípios gerais, destinados ao ensino de todas as disciplinas, e os conteúdos do tópico referente à matemática, os quais procuramos articular com os depoimentos das normalistas. Diante do questionamento, anteriormente apontado, este trabalho relata, a seguir, o papel da Didática Geral e Especial no Curso Normal do IERP - devido a uma das aluna ter mencionado que o manual foi usado nas aulas de Didática -, traz algumas informações sobre a Colted e busca interpretar de que forma as orientações sobre o que ensinar e como ensinar matemática, contidas no manual $O$ livro didático: sua utilização em classe, estavam presentes no Curso Normal do IERP, no final da década de 1960 e início da década de 1970

\section{O papel da Didática Geral e Especial no Curso Normal do IERP}

Moreira (2012) explica que as discussões sobre o currículo no Brasil têm sua origem nas décadas de 1920 e 1930, quando importantes transformações foram realizadas no 
contexto econômico, cultural, social e político de nosso país, período em que emergia a industrialização e, assim, colocava-se a necessidade de escolarizar as massas, a fim de favorecer o desenvolvimento econômico e romper com o poder da oligarquia rural. Nesse momento, os pioneiros da Escola Nova buscaram superar o ensino tradicional, propondo novas formas de conceber o ensino.

Consideramos pertinente destacar que o surgimento das disciplinas antecedeu ao interesse em discutir o currículo. De acordo com Hofstetter e Schneuwly (2017b), com o novo sistema de produção científica que se estabeleceu a partir da virada dos séculos XVIII e XIX, a ciência que, até então era pensada como uma unidade, sofreu uma reconfiguração diante do grande crescimento de práticas de pesquisas, em parte, impulsionadas pelas demandas sociais, profissionais, culturais e econômicas. Ocorreu então a especialização, tanto das instituições, como das pesquisas, e assim surgiram as especializações disciplinares. Nesse contexto, as disciplinas se constituem a partir das relações de conflito, concorrência, aliança ou cooperação (HOFSTETTER; SCHNEUWLY, 2017b).

Ao observarmos o conjunto de disciplinas do currículo do Curso Normal do IERP, oferecidas no período de 1969 a 1972, percebemos algumas mudanças. O Quadro 1 nos dá uma visão disso.

Quadro 1 - Disciplinas ministradas no Curso Normal do IERP (1969-1972)

\begin{tabular}{|c|c|c|c|}
\hline \multicolumn{4}{|c|}{ Período de formação de Jacy Andrade Sturken } \\
\hline \multirow[b]{2}{*}{$\begin{array}{l}\text { Disciplinas } \\
\text { ministradas no } \\
\text { período de } 1969 \\
\text { a } 1971\end{array}$} & 10 ano & 20 ano & 3ㅇ ano \\
\hline & $\begin{array}{lr}\text { Português; } & \text { Matemática; } \\
\text { Estatística; } & \text { Biologia } \\
\text { Educacional; Psicologia } \\
\text { Geral; Estudos Sociais; } \\
\text { História e Geografia; } \\
\text { Educação Moral e Cívica e } \\
\text { Ciências Sociais. }\end{array}$ & $\begin{array}{l}\text { Português; Matemática } \\
\text { e Estatística; Psicologia } \\
\text { Educacional; Didática } \\
\text { Geral; Higiene e } \\
\text { Puericultura; História da } \\
\text { Educação e Educação } \\
\text { Moral e Cívica. }\end{array}$ & 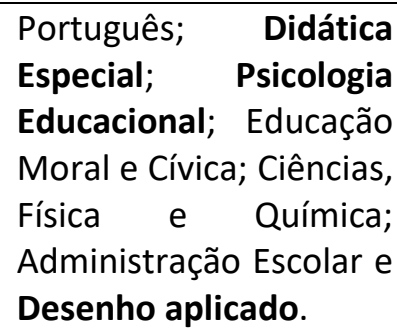 \\
\hline \multicolumn{4}{|c|}{ Período de formação de Nina Rosa Braga Cardoso } \\
\hline Disciplinas & 10 ano & 20 ano & 3ㅇaㅇ a \\
\hline
\end{tabular}




\begin{tabular}{|c|c|c|c|}
\hline \multirow{6}{*}{$\begin{array}{l}\text { ministradas no } \\
\text { período de } 1970 \\
\text { a } 1972\end{array}$} & Psicologia & \multirow{2}{*}{$\begin{array}{l}\text { Português; Matemática } \\
\text { e Estatística; Psicologia }\end{array}$} & \multirow{2}{*}{$\begin{array}{l}\text { Português; Psicologia } \\
\text { da Aprendizagem; }\end{array}$} \\
\hline & Geral; Matemática e & & \\
\hline & Estatística; & Educacional; Didática & Ciências, \\
\hline & Geral; Estudos Sociais; & Especial; & Química; \\
\hline & Geografia e História; & Moral e Cívica; História & Especial; Administração \\
\hline & $\begin{array}{l}\text { Organização Social e } \\
\text { Política do Brasil; } \\
\text { Educação Moral e Cívica; } \\
\text { Biologia Educacional. }\end{array}$ & $\begin{array}{l}\text { da Educação; Higiene e } \\
\text { Puericultura. }\end{array}$ & $\begin{array}{l}\text { Escolar; Educação Moral } \\
\text { e Cívica e Desenho } \\
\text { aplicado. }\end{array}$ \\
\hline
\end{tabular}

Fonte: Pastas dos estudantes concluintes do Curso Normal do IERP nos anos de 1971 e 1972.

Destacamos, no Quadro 1, as disciplinas que, com base nos depoimentos, interpretamos ter uma relação com o ensino de matemática, ou seja, aquelas que abordavam os saberes a ensinar e os saberes para ensinar a matemática. Percebemos, com base na nomenclatura, que, no ano de 1969, havia a disciplina Matemática e a disciplina Estatística, mas, no ano de 1970, ambas se fundiram em uma só. A discente Jacy Andrade Sturken cursou a disciplina Didática Geral, no segundo ano, e, Didática Especial, no terceiro ano, já a discente Nina Rosa Braga Cardoso cursou Didática Geral, logo no primeiro ano, e, Didática Especial, no segundo e no terceiro anos. Ao que parece foi dada, a partir de 1970, uma maior importância à disciplina Didática Especial.

Mattos (1968, p. 51) conceituou a Didática como uma "disciplina pedagógica de caráter prático e normativo que tem por objetivo específico a técnica do ensino, isto é a técnica de dirigir e orientar eficazmente os alunos e sua aprendizagem." A Didática é apresentada pelo autor como um conjunto de normas, técnicas, recursos e procedimentos, que tem a especificidade de ensinar a ensinar. Embora a didática apresentasse essa especificidade, segundo Mattos (1968), ela não apresentaria uma melhor técnica de ensino de forma absoluta, mas orientaria a ação docente, dentro de determinados contextos, com base em conhecimentos provenientes da Filosofia Educacional, Biologia, Psicologia e Sociologia da educação e em experimentações e práticas que se mostrassem eficazes no ensino moderno.

Mattos (1968) também apresentou uma distinção entre Didática e Metodologia, para ele, a Metodologia se limita ao estudo do método, se refere apenas ao tratamento metódico de uma disciplina, enquanto a Didática, além de estudar a metodologia, também abrange outros aspectos educativos da formação da personalidade dos alunos. Mattos (1968) também distingue a Didática Geral da Didática Especial, segundo o citado autor a Didática Geral 
constitui a teoria fundamental do ensino, dá ênfase ao estudo dos critérios, normas, métodos procedimentos de ensino e problemas que envolvem o processo de ensino e aprendizagem, tais discussões servem para nortear o processo de ensino e aprendizagem de forma geral. Já a Didática Especial restringe essas discussões da Didática Geral a uma determinada matéria de estudo, a partir de uma análise da especificidade de cada uma. Assim sendo, salientamos o que relata a discente Magnólia Santana de Farias (2017), concluinte em 1962:

A gente tinha Didática que falava uma parte da didática da matemática. Mas, voltado para o ensino de matemática na escola primária. [...] a Didática Geral abrangia tudo, Matemática, Geografia, História, Ciências. Na Didática orientava como ensinar no primário.

Pintassilgo e Pedro (2017) contam que, em Portugal, as disciplinas Didática Especial e Didática Geral, na escola do magistério primário, atendiam a essa mesma perspectiva, já que a Didática Geral se debruçava no estudo de métodos, processos e modos de ensino com caráter genérico, enquanto a Didática Especial se dedicava ao estudo de uma determinada matéria - Didática da Aritmética, Didática da Leitura, Didática das Ciências, Didática do Desenho etc. - analisando a especificidade de cada disciplina e as dificuldades no seu ensino, a fim de proporcionar ao professorando uma compreensão mais fácil e profunda, e assim, facilitar o processo de aplicação dos conhecimentos específicos, ou seja, a citada disciplina tinha um caráter essencialmente prático. Os autores ainda afirmam que a Didática Especial desempenhou um papel fundamental na formação dos professores do primário e tinha suas raízes no escolanovismo.

O Quadro 1, que traz as disciplinas ministradas no referido recorte temporal, ajuda a perceber que houve uma mudança na oferta da disciplina Psicologia. Nos anos de 1969 a 1971, os discentes estudavam Psicologia Geral, no primeiro ano, e Psicologia Educacional, no segundo e terceiro anos. Já os discentes que ingressaram em 1970 tiveram Psicologia Geral, no primeiro ano, Psicologia Educacional, no segundo ano e Psicologia da Aprendizagem, no terceiro ano. Não podemos inferir se a mudança de nomenclatura acarretou de fato em modificação de conteúdos abordados na disciplina Psicologia no terceiro ano, mas julgamos válido salientar que as discentes Jacy Andrade Sturken e Nina Rosa Braga Cardoso ressaltaram em seus depoimentos a importância que o Curso Normal do IERP dava ao ensino de Psicologia.

Essas mudanças apresentadas no currículo do Curso Normal do IERP nos remetem a 
Chervel (1990), quando ele destaca que as várias disciplinas mantêm entre elas uma solidariedade didática, assim, por trás de uma denominação única, há de se questionar se elas escondem duas ou três disciplinas distintas. Portanto, a evolução da terminologia pode ser esclarecedora. Hofstetter e Schneuwly (2017b), por sua vez, dizem que as disciplinas se constituem a partir da relação que possuem entre si, em um movimento de incessante reconfiguração que inclui a interdisciplinaridade, a qual é concebida pelos autores não somente como uma colaboração entre as disciplinas, mas também como uma ligação estabelecida a partir de concorrências, conflitos ou colaboração.

O manual intitulado O livro didático: sua utilização em classe, publicado pela Colted destinado à formação de professores primários, encontrado no IERP, também demonstra uma preocupação com a formação específica para o como ensinar as disciplinas, dentre elas a matemática. A seguir veremos alguns aspectos da abordagem do livro e de que forma os saberes abordados por ele estiveram presentes na formação dos normalistas do Curso Normal do IERP.

\section{Colted: algumas de suas propostas}

A história do ensino da matemática foi marcada por discussões em torno do livro didático, realizadas em conferências, congressos, entre outros, resultando em recomendações de alguns livros, bem como em avaliações negativas de livros, que eram utilizados no ensino da citada disciplina. Em 1959, em Genebra, realizou-se a XXII Conferência Internacional de Instrução Pública com o intuito de estabelecer recomendações com relação à elaboração, à escolha e à utilização de livros didáticos. Nessa conferência, representantes de 57 países reconheceram, por unanimidade, a necessidade de o Estado oferecer, aos alunos, livros e outros materiais didáticos, necessários para a promoção do ensino e da aprendizagem. O governo brasileiro, percebendo a importância do livro didático para a melhoria do rendimento escolar, e diante da necessidade de suprir os estudantes com livros adequados, criou a Comissão do Livro Técnico e do Livro Didático (Colted), pelo decreto 59.355, de 04 de outubro de 1966 (COLTED, 1970).

O citado decreto afirma que essa Comissão foi instituída por considerar a importância e a influência do livro didático e do livro técnico na política de educação e de desenvolvimento 
econômico e social do País e, sendo assim, o Estado devia manter-se numa atitude, ao mesmo tempo, atuante e vigilante, tendo em vista seu interesse, tomando o cuidado para não asfixiar a produção intelectual da iniciativa privada (BRASIL, 1966). A Colted buscou distribuir livros para bibliotecas de escolas de nível primário, médio e superior, a fim de criar núcleos de bibliotecas, enriquecer o acervo das existentes e oferecer ao professorado livros selecionados por equipes de especialistas. Dentre os livros que integraram a biblioteca Colted estavam: livros didáticos e livros de consulta para professores, livros informativos e livros didáticos para alunos, guias para professores, literatura infantil, livros de Psicologia, metodologia, currículo e supervisão, entre outros (COLTED, 1970).

O programa desenvolvido pela Colted também propôs a aquisição de livros didáticos e a distribuição destes em escolas primárias e a oferta de cursos de treinamento para professores de escolas primárias, de modo a atingir os professores de municípios contemplados por donativo de livros, com o propósito de capacitá-los para o uso deles. Os objetivos apontados pelo programa eram: discutir e apontar critérios para a escolha do livro didático e analisar os princípios que determinavam a boa escolha do livro, visando transformálo em um recurso básico para a aprendizagem do aluno e para o desenvolvimento de sua capacidade de trabalho independente (COLTED, 1970).

Diante de tais objetivos, era dada aos instrutores a incumbência de obter, por intermédio do treinamento realizado, uma nova atitude do professor, no que diz respeito à conceituação, à seleção e à utilização do livro didático; de provocar o professor à mudança de comportamento, tendo em vista o aperfeiçoamento do livro e a elevação do rendimento escolar; e de motivar o professor a utilizar o material de instrução programada, a consultar o material de classe e a bibliografia indicada e a avaliar, previamente, os livros que seriam adotados e o resultado obtido pelo uso deles em todos os tipos de turma (COLTED, 1970). Isso posto, acreditamos que as propostas dos livros publicados e distribuídos pela Colted podem ter influenciado a prática de alguns professores primários, uma vez que foi o próprio Estado quem criara e financiara as ações da Comissão.

Além disso, essas ações não se restringiam à seleção e à distribuição de livros, mas também abrangiam o treinamento de professores. Conjecturamos que tais ações eram propostas no intuito de não só convencê-los de que os livros distribuídos pela citada Comissão 
contribuíam para a qualidade do ensino, como também capacitá-los para o uso do livro didático, tendo em vista os objetivos propostos pela Colted. Sendo assim, consideramos pertinente interpretar algumas das orientações contidas no manual intitulado $O$ livro didático e sua utilização em classe, encontrado na Biblioteca do IERP.

\section{Orientações sobre como utilizar o livro didático}

Conforme relatamos anteriormente, havia uma preocupação por parte da Colted em ensinar os professores a utilizarem o livro didático. O manual intitulado O livro didático e sua utilização em classe, apresentado pela Colted como um material básico dos cursos de treinamento para professores primários, explicita em sua primeira unidade essa preocupação. Nesse livro há uma apresentação de aspectos gerais, no primeiro capítulo, e, nos seguintes, orientações para o ensino em áreas específicas, conforme podemos ver na imagem do sumário, na Figura 1.

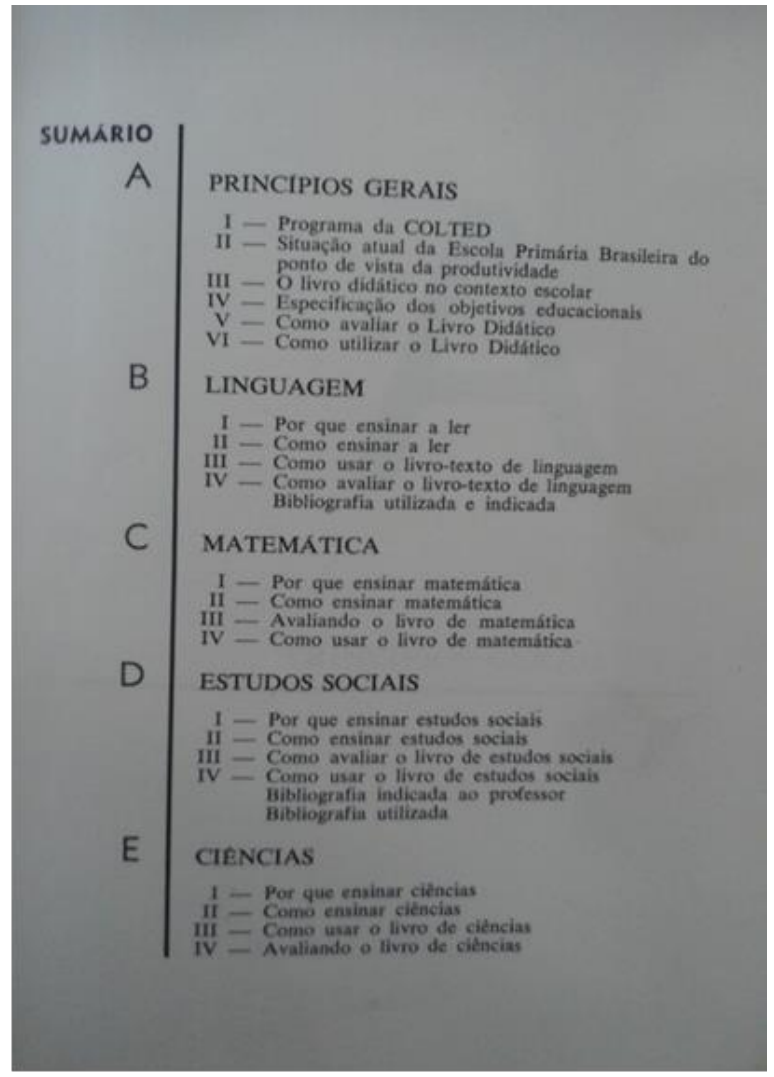

Figura 1 - Sumário do livro: O livro didático: sua utilização em classe. Fonte: COLTED, 1970, p. 16

Nos princípios gerais, além de apresentar a criação da Colted e sua proposta, há 
também uma contextualização do ensino primário no Brasil, destacando aspectos relacionados ao índice de crianças escolarizadas e não escolarizadas, à evasão e à repetência, à necessidade de atender às particularidades dos alunos e de favorecer o sucesso escolar de todos. Em seguida, na unidade III, é conceituado o livro didático e são ressaltadas algumas das implicações do seu uso no processo de ensino e aprendizagem; na unidade IV é exposto o conceito e os tipos de objetivos, e discutidos aspectos da avaliação; na unidade V e VI constam orientações aos docentes acerca de como avaliar e como utilizar o livro didático, respectivamente. Ao término da apresentação dos princípios gerais, o livro apresenta dois anexos, o primeiro com informações sobre interesses das crianças, considerando a faixa etária; e o segundo, sugestões para o exame e a avaliação do livro didático.

O Tópico em que é abordado como usar o livro didático no ensino de matemática é o C, conforme podemos observar na Figura 1. Essa parte do livro se divide nas seguintes unidades: I - Por que ensinar matemática; II -Como ensinar matemática; III - Avaliando o livro de matemática e; IV - Como usar o livro de matemática. A unidade I da parte C é iniciada remetendo os leitores à importância da matemática na década de 1970, destacando as mudanças que ocorreram ao compará-la ao passado, em que a indústria e o comércio eram menos desenvolvidos. De acordo com Jacy Andrade Sturken (2017), - aluna do Curso Normal do IERP, no período de 1969 a 1970 - em Jequié, o período de 1969 até 1974,

[...] foi uma época de grande desenvolvimento econômico, a indústria se expandiu e novos postos de trabalho surgiram. Começaram a chegar em nossa cidade a Indústria de confecções, surgiram a Esmerc, Estrela, Saci Pererê. Foi um momento crucial e marcante para Jequié, tornando-se um polo têxtil.

Nesse contexto de industrialização, que também ocorria em âmbito nacional, a Colted (1970) ressaltou que o ensino de matemática não poderia ser desenvolvido da mesma forma que outrora, em que se supervalorizavam a memorização de regras e fórmulas e a mecanização dos processos de calcular. Esse posicionamento nos remete a Chervel (1990), quando trata dos conteúdos e dos métodos adotados pelas disciplinas que eram decorrentes de consensos abstraídos de discussões, que eram realizadas considerando as finalidades e os resultados que eram propostos para o ensino de determinada disciplina, em distintos contextos históricos. 
A Colted (1970) defendia que o ensino de matemática deveria objetivar a compreensão, valorizar a importância do desenvolvimento da matemática como um sistema de ideias ou conceitos, a fim de satisfazer as necessidades daquele tempo e de preparar os alunos para o futuro, tendo o cuidado de não abandonar a estrutura fundamental da disciplina. Assim, apresentou três tipos de objetivos para o seu ensino, foram eles:

\footnotetext{
- Objetivo matemático, relacionado ao desenvolvimento de habilidades e técnicas básicas, redescoberta de fatos e princípios, emprego do vocabulário matemático correto;

- Objetivo social, relacionado ao desenvolvimento da habilidade de analisar as situações-problema, a fim de que a criança se torne capaz de resolvê-las em sua própria vida;

- Objetivo relacionado ao desenvolvimento da criatividade, hábitos, atitudes e valores desejáveis (COLTED, 1970, p. 124).
}

A Colted (1970, p. 39) definia objetivo como "um ponto a que deve atingir alguém, quando termina sua experiência". No manual que analisamos é destacada a relevância do planejamento do ensino e são apresentadas várias orientações com relação à proposição de objetivos, métodos, critérios avaliativos e utilização de recursos didáticos (COLTED, 1970). Nesse sentido, Jacy Andrade Sturken (2017) conta da importância dada ao plano de aula durante o estágio, do Curso Normal do IERP. A discente afirma que tinha um caderno com planos de cada aula, nos quais eram descritos os objetivos, as atividades realizadas, as avaliações, destaca, também, que suas aulas eram sempre supervisionadas.

Segundo a Colted (1970), o objetivo matemático nas escolas primárias era levar as crianças a somar, subtrair, dividir e multiplicar números inteiros, decimais e fracionários, além de apresentar aos alunos conhecimentos básicos de unidades de medidas, percepção e mensuração de formas e sistema monetário, por acreditar que estes conhecimentos e habilidades poderiam satisfazer suas necessidades matemáticas fundamentais na vida em sociedade. Os conteúdos apresentados pela Colted são destacados pela depoente Nina Rosa Braga Cardoso (2017), quando narra que, no Curso Normal do IERP, o ensino de matemática:

\footnotetext{
Era baseado no que iria ensinar no primário. Eu lembro até que o programa chegava até o assunto de fração, passava pelas quatro operações, começava com conjunto. Eram os assuntos que a gente ia ensinar: as quatro operações, expressões numéricas, eram regras de divisibilidade, que são regras que ensinam a descobrir quais os números divisores de outros números. Era isso, a gente aprendia o que ia facilitar a vida da gente. Problemas, principalmente problemas, números primos através do crivo de Eratóstenes, tudo que ia ensinar no primário.
} 
Diante do exposto, percebemos que o ensino de matemática no Curso Normal do IERP, no final da década de 1960 e início da década de 1970, dava ênfase aos conteúdos que seriam ministrados no primário, assim como era proposto no manual da Colted, intitulado $O$ livro didático: sua utilização em classe. Segundo o excerto do depoimento de Jacy Andrade Sturken (2017), a seguir, e a disposição de disciplinas na grade curricular do curso, exposta anteriormente, interpretamos que os saberes a ensinar foram priorizados no primeiro ano do curso e, nos anos seguintes, o enfoque foram os saberes para ensinar matemática. Vejamos:

\begin{abstract}
Olha, no Curso Normal, o primeiro ano de Magistério a gente estudou matemática mesmo, não foi nada de didática, [...] foi uma revisão de matemática.

[...] Agora, já no segundo e terceiro ano não, era metodologia, era didática, no segundo ano e terceiro ano era didática da matemática e na terceira unidade o estágio, se fazia o estágio.
\end{abstract}

Ao observarmos os depoimentos das citadas discentes, percebemos que, na disciplina Didática, os saberes para ensinar eram apresentados de forma articulada aos saberes a ensinar matemática. Essa observação é ratificada por Nina Rosa Braga Cardoso (2017), quando afirma que, em Didática, "[...] estudávamos conjuntos aprendendo como ensinar".

Nina Rosa Braga Cardoso (2017), para além do estudo de conjuntos, também ressalta em seu depoimento a importância dada ao ensino de frações, "Em conjuntos a gente aprendia: intersecção... união, eu não lembro mais... e tudo sobre fração". Com relação ao objetivo social, a Colted (1970, p. 124) pontuava que "a criança deve ser levada a sentir que a Matemática funciona em sua vida, ajudando-a a resolver os problemas quantitativos que surgem a cada instante". Assim sendo, é válido ressaltar que Jacy Andrade Sturken (2017), ao descrever as aulas de Didática, relata que:

Quando eu fui aluna, matemática eu só estudei no primeiro ano e estudei como ensinar matemática, como ensinar matemática era realmente... uma aula aos moldes tradicionais mesmo, você jogar a expressão no quadro, o problema no quadro, era quadro, giz e pronto. Não havia essa simulação de ir em um supermercado, em uma venda [...].

Contudo, reconhece ela que, embora as aulas não fossem apresentadas de forma dinâmica, os professores orientavam algumas atividades que levavam os alunos a utilizarem a matemática em seu cotidiano.

[...] tinha muitos professores bons que tinha essa abertura, porque não se pode só a matemática com o giz e o quadro de giz, que não era uma lousa não, era o quadro de giz, mas já se dizia: - Gente leva no supermercado, já 
tinha essa... já se falava, não se fazia isso no Colégio, mas você podia fazer. Já se tinha essa abertura. [...] você podia levar o aluno no mercadinho e vê que a anotação era feita na caderneta, com a venda a prazo [...] A gente podia levar o aluno, tinha uma livre orientação para trabalhar, [...] (STURKEN, 2017).

Nesse sentido, a citada discente destaca uma experiência de estágio, na qual levou os alunos a perceberem como a matemática da escola era utilizada na vida diária deles.

Olha, quando eu fui estagiária, estagiei no Grupo Escolar Fernando Barreto, a matemática dependia muito da criatividade de cada um, a gente trabalhava com algumas técnicas, já em 1971 eu trabalhava matemática com vendas, com apresentação de quilos, levava os quilos de arroz, isso aí dependia de cada um usar a criatividade que tinha, porque o professor ensinava de uma forma, mas se o aluno fosse interessado lá dentro fazia mil coisas. Então já se trabalhava com o quilo, eu levava, aí falava: - Olha aqui é um quilo, meio quilo é metade, eu trabalhava assim, eu fiz um estágio muito bom, graças a Deus (STURKEN, 2017).

Vemos que as atividades realizadas por Jacy revelam indícios dos ideais da Escola Nova. Nesse contexto educativo em que há uma ênfase na prática para aprendizagem, o aluno tornase um sujeito ativo. Estudos na área da Psicologia argumentam que essa prática só conduz ao aperfeiçoamento do ensino da matemática, quando for acompanhada por motivação para aprender e quando a aprendizagem ocorrer numa situação significativa para o aluno.

O terceiro objetivo, apontado no manual da Colted, diz respeito ao objetivo relacionado à criatividade, aos hábitos, às atitudes e aos valores desejáveis.

O professor deve estimular a curiosidade da criança, levando-a a sentir prazer em explorar idéias novas, a desenvolver a eficiência no hábito da leitura e o hábito de estudar, essenciais a uma aprendizagem independente em Matemática.

Valores e atitudes são também importantes. Assim, se se pretende preparar o indivíduo em Matemática, é preciso levá-lo a usar esse conhecimento para conquistas positivas que contribuam para a felicidade do Homem, no sentido de ajudá-lo a pensar criativa e logicamente (COLTED, 1970, p. 124).

Essas ideias também estiveram presentes na formação das estudantes do Curso Normal do IERP. Podemos perceber isso quando Nina Rosa Braga Cardoso (2017) relata o interesse do curso em discutir aspectos relacionados ao comportamento dos alunos, na disciplina Psicologia, vejamos:

O que mais se estudava era a psicologia da criança, para entender as atitudes da criança. A gente tinha que compreender o porquê que a criança era de determinado jeito ou deixava de ser.[...]

Eu lembro bem que ensinava sobre o ego do aluno para entender as atitudes, o desenvolvimento da criança. 
Esse depoimento nos leva a pensar que a citada disciplina, voltada para os saberes para ensinar, apresentava uma preocupação em habilitar os futuros professores para lidarem com aspectos comportamentais dos estudantes. Jacy Andrade Sturken (2017), nessa mesma perspectiva, menciona estratégias, utilizadas em seu estágio, as quais tinham a intencionalidade de levar os alunos a mudarem de atitude, observemos:

\begin{abstract}
No dia em que eu cheguei na sala de aula, no estágio, em 1971 [...]. Então a professora, ela me chamou particularmente e me falou: tem uns alunos, fulano, fulano e fulano, esses meninos, eles me dão um pouquinho de trabalho. $\mathrm{O}$ que foi que eu fiz, todos os dias, eu falava assim: Até terminar o meu estágio, todo dia um aluno vai tomar conta da sala, da disciplina, de quem estiver conversando, quem não estiver prestando atenção na aula vai anotar, mas vamos começar primeiro por... Eu vou escolher, escolhi o pior aluno da sala que a professora tinha feito a referência. Pronto! Acabou o problema, isso eu passei até para minhas alunas, porque você tem que valorizar, precisa melhorar a autoestima do aluno, não pode dar reforço negativo.
\end{abstract}

No que diz respeito ao estímulo à criatividade da criança e à promoção do sentimento de prazer e exploração de ideias, por parte do aluno, o depoimento de Jacy Andrade Sturken (2017) faz menção a orientações neste sentido, conforme vimos anteriormente. Nina Rosa Braga Cardoso (2017) também indica uma atividade que, segundo ela, tinha o propósito de estimular a criatividade e a curiosidade dos alunos.

\begin{abstract}
Ah, uma coisa que eu lembro que ensinava na Didática com a matemática era uma estratégia que se usava para conhecer os números primos e os múltiplos. Era o crivo de Eratóstenes, era como você identificava numa tabela os números primos. Fazia uma tabela com todos os números, daí ia contando de dois em dois e ia riscando, aí achava os múltiplos de dois, depois íamos riscando de três em três, achávamos os múltiplos de três, quando terminava a tabela, aqueles números que estavam riscados eram múltiplos de algum número, os que não tinham risco eram os números primos, porque eles só são divisíveis por um e por eles mesmos. Era uma forma lúdica de ensinar, uma coisa gostosa de se fazer.
\end{abstract}

Desse modo, fica ainda mais perceptível a proposta de articular os saberes abordados no Curso Normal para o ensino da matemática, cujas intenções da escolarização primária estão de acordo com uma pedagogia que buscava na atividade sua validação, uma pedagogia nova que dava proeminência à construção experimental do conhecimento pelo estudante e à regulação das práticas escolares (VIDAL, 2010).

Chervel (1990) destaca a importância dos saberes pedagógicos no processo de ensino e aprendizagem, os quais são elaborados tendo em vista as finalidades da educação, entre as 
quais, podemos citar: o ensino de exposição, os exercícios, as práticas de motivação. Todos esses aspectos estavam presentes na formação das normalistas do Curso Normal do IERP, no final da década de 1960 e início da década de 1970. Alguns desses saberes também são elencados no manual da Colted, que estamos analisando neste artigo.

Na unidade II do livro da Colted (1970) em questão, consta a discussão sobre o tema "Como ensinar matemática", em que se ressalta que o bom ensino é aquele em que o professor leva a criança a alcançar o objetivo proposto. Ainda afirma que "o professor terá de conduzi-la à realização de experiências matemáticas, através de métodos eficientes e material conveniente, para levá-la à redescoberta de princípios e à formação de conceitos" (COLTED, 1970, p. 125). Nesse sentido, a Colted salientava a importância do uso de materiais concretos, observações e experimentações por possibilitarem às crianças chegar a generalizações matemáticas. Atividades nesse âmbito foram relatadas por Jacy Andrade Sturken, conforme podemos ver no excerto abaixo.

[...] trabalhava também assim, por exemplo, esses dois (pegando dois papéis) com esses dois, no final dá quanto?

[...] para ensinar a tabuada, a tabuada é decorada, mas você precisa levar essa tabuada para a prática[...]

[...] por exemplo, levar vários copos, e somava, multiplicava. Subtende-se que o aluno que está na Escola Normal ele já sabe as quatro operações, não precisa mais de tabuada, mas para ele aprender a ensinar a tabuada, ele utilizava de alguns artifícios práticos. Outro exemplo, a gente levava um litro de garrafa, um litro de metal, trabalhava com copos: _tem 4 copos, você tira 2 , quanto é que fica?

O relato de Jacy nos permite interpretar que as orientações do Curso Normal do IERP, no período em estudo, eram realizadas também mediante uma apropriação da concepção pedagógica do método do escolanovismo, em que o docente buscava conduzir a aprendizagem da matemática, por intermédio do oferecimento de situações, em que o aluno pudesse elaborar seu próprio conhecimento a partir da observação e também da ação.

Diana Gonçalves Vidal (2010), no texto “Escola Nova e processo educativo”, publicado no livro 500 anos de Educação no Brasil, afirma que, na década de 1920, a escola renovada passou a servir de base à disseminação de valores e normas sociais em sintonia com as necessidades da nova sociedade, no contexto de modernização que se fundamentava nos preceitos do trabalho produtivo e eficiente; na velocidade das transformações; na internalização de normas e comportamentos, em termos de tempos e movimentos; e na 
valorização das propostas da Psicologia experimental, tomando o ser humano em sua dimensão individual. Assim sendo, o aluno assumia o centro do processo educativo, e os materiais da escola eram de fundamental importância para a construção experimental do conhecimento pelo estudante. Sendo assim, "aprofundava-se aqui a viragem iniciada pelo ensino intuitivo no fim do século XIX, na organização das práticas escolares. Deslocado do 'ouvir' para 'ver', agora o ensino associava 'ver' e 'fazer'"' (VIDAL, 2010, p. 498).

Na unidade III são apresentados três tipos de materiais, que podem ser utilizados no ensino de matemática, são eles: material exploratório que pode ser objetos do meio ambiente (alunos, giz, janelas etc.) e objetos que representam ideias matemáticas (partes fracionárias, números em cores); material pictórico (gravuras, desenhos etc.) que pode ser utilizado na ausência do material exploratório; material simbólico (impressos e principalmente livros) que favorece a expansão dos conceitos matemáticos e tem grande relevância para a aprendizagem independente. Diante da importância dada ao livro didático pela Colted, a unidade III apresenta como tema "Avaliando o livro de matemática". Essa unidade está dividida em três subtópicos, são eles: Conceituação; Característica de um bom livro-texto de matemática; e Como examinar e selecionar os livros-texto de matemática.

A Colted apresentava o livro-texto de matemática como um instrumento de aprendizagem, utilizado como suporte para o ensino na escola. Nessa perspectiva, não creditava ao livro a obrigatoriedade de conter todo o programa de ensino no ano letivo, já que o professor poderia completá-lo e adaptá-lo às especificidades do programa e da classe. Considerando a possibilidade de desatualização do professor, bem como o exíguo tempo para planejamento e a escassez de recursos e fontes de consulta, a Colted recomendava que o livro texto fosse acompanhado de um guia de ensino, o qual deveria apresentar os seguintes aspectos:

a) Esclarecimentos sobre os princípios psicológicos que norteiam as atividades previstas no livro do aluno para conduzi-lo à aprendizagem;

b) Fundamentação básica, resumida, sobre o conteúdo matemático desenvolvido no livro do aluno;

c) Sugestões de como explorar as diferentes páginas, unidades e áreas que compõem o livro do aluno;

d) Sugestões de atividades e de recursos didáticos variados para enriquecer o programa e adequar o livro a todas as crianças, tanto as de aprendizagem lenta, como as de aprendizagem mais rápida (COLTED, 1970, p. 128). 
Isso evidencia a importância dada pela Comissão aos saberes da Psicologia, os quais, conforme mencionamos anteriormente, eram preponderantes no Curso Normal do IERP. A relevância dada a esse tipo de conhecimento era tão significativa, que Nina Rosa Braga Cardoso (2017) destacou em seu depoimento que "A psicologia que eu estudei no Curso Normal foi a psicologia da criança, a gente saía quase psicólogo".

A análise do livro em questão ratifica a relevância dos conteúdos, as sugestões de utilização de recursos didáticos variados, aspectos também apontados pelas depoentes, conforme já relatado. Quanto à utilização de livros didáticos, as depoentes não afirmaram têlos usado durante o estágio. Ao caracterizar um bom livro texto de matemática, a Colted enfatizava que esse deveria valorizar o conceito e as habilidades computacionais; utilizar desenhos e diagramas; sugerir o uso de materiais concretos para o ensino de matemática; introduzir as ideias matemáticas, relacionando-as às experiências diárias dos alunos; e ressaltar a aplicação da matemática às situações da vida. A Colted ainda ressaltava que um bom livro-texto de matemática:

Unifica e integra idéias e processos matemáticos, ressaltando conceitos básicos como a noção de conjunto, sistema decimal de numeração, sistema numérico e suas propriedades, o conceito de relação etc. e sua inter-relação com as demais áreas da Matemática. Desenvolve noções precisas, apresentando um conteúdo atualizado, tendo em vista o que as pesquisas, estudos e experimentações revelam sôbre a matéria, evidenciando assim, os rumos traçados pela Matemática Moderna, sem tomar, contudo, uma posição extremada (COLTED, 1970, p. 128).

Consideramos pertinente destacar que, embora a discente Nina Rosa Braga Cardoso (2017) diga que o Curso Normal do IERP dava enfoque ao estudo de conjuntos, essa ênfase não é apontada pela discente Jacy Andrade Sturken, que o concluiu em 1971. O que nos remete a Chervel (1990, p. 204), quando afirma que "a história das disciplinas se dá frequentemente por alternância de patamares e de mudanças importantes, até mesmo de profundas agitações". Essas agitações representam o momento em que uma antiga doutrina ensinada entra em crise, é submetida a turbulências e ocasiona uma mudança, em que uma antiga vulgata é substituída. Essa modificação não ocorre de forma instantânea, pois o antigo sistema coabita com o novo, em proporções variáveis até que os novos métodos ganhem maior território que o antigo e alcancem estabilidade até que seja novamente perturbada diante das inevitáveis variações (CHERVEL, 1990). 
Estudos realizados por Braga e Dias (2010) mostram relatos de professoras que participaram de cursos oferecidos pelo Programa de Treinamento e Aperfeiçoamento de Professores de Ciências Experimentais e Matemática (PROTAP), na década de 1970. Tais cursos tinham o objetivo de preparar os docentes para o ensino da matemática moderna nos municípios do interior do estado da Bahia. Dentre os docentes entrevistados por esses autores, está a professora do IERP, Marileide Duarte Leal, que conta a resistência por parte dos docentes de matemática quanto à implementação das propostas do Movimento da Matemática Moderna no IERP.

Acreditamos que essa afirmação de Marileide Duarte Leal pode explicar a diferença no ensino de conjuntos, apontada pelas discentes do Curso Normal. Isso posto, é válido ressaltar que, de acordo com Chartier (2002), a realidade é apreendida pelos sujeitos de maneira diferenciada, pois eles têm uma forma própria de estar no mundo. Embora o sistema busque impor regras e normas, tendo em vista um objetivo, esse sistema não anula as possibilidades de escolha e negociação que os indivíduos possuem.

No intuito de garantir aos professores habilidades e conhecimentos para a seleção de um bom livro de matemática, a Colted (1970) fazia algumas recomendações a serem consideradas no processo de seleção, como: utilização de uma ficha com os dados dos livros analisados, valorização de livros publicados ou revistos nos últimos cinco anos e ainda a verificação de o livro ter sido estruturado de acordo com o método da descoberta. Em caso de empates entre livros, o professor deveria fazer a análise de um conteúdo específico e responder alguns questionamentos como: qual dos livros ensina melhor esse conteúdo específico, qual dos livros desenvolve melhor esse tópico, qual dos livros aborda melhor essa área.

Tendo em vista a unidade III, observamos que a Colted dava grande importância ao processo de escolha de livros, por entender seu potencial para a aprendizagem dos alunos. Essa Comissão também demonstrava preocupação em capacitar o professor para a utilização do livro didático de matemática, pois faz na unidade IV recomendações sobre como usar o livro dessa disciplina.

Nessa unidade é enfatizado que, se o livro for usado como único recurso, o professor acaba restringindo o seu papel. O professor precisa utilizar situações do cotidiano da criança, 
a fim de ajudá-la a se envolver e compreender como aplicar o conhecimento matemático em sua vida. No entanto, o livro também não pode ser desprezado. O professor não pode utilizar apenas materiais exploratórios e pictóricos, pois o trabalho pode desorganizar-se ou a exposição oral ser mal ou parcialmente compreendida. Além disso, o livro serve como apoio para estudos subsequentes ou para expansão de conceitos que já foram formados.

A Colted ressalta várias sugestões que o livro didático de matemática sugere ao professor, entre as quais estão:

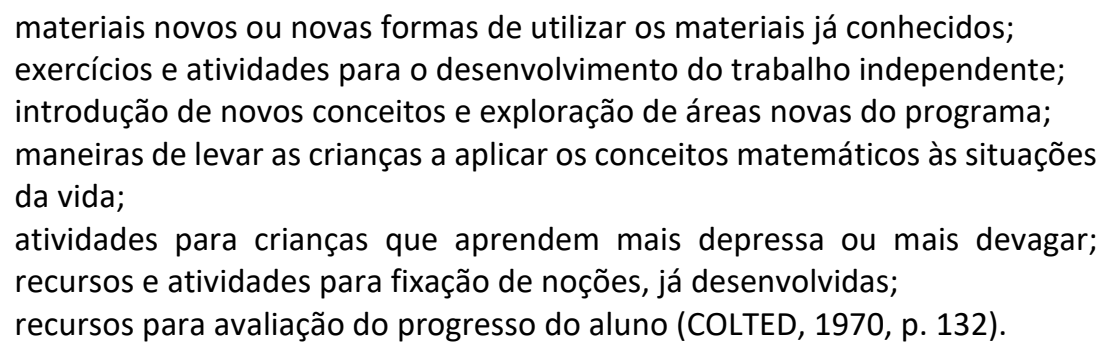
exercícios e atividades para o desenvolvimento do trabalho independente; introdução de novos conceitos e exploração de áreas novas do programa; maneiras de levar as crianças a aplicar os conceitos matemáticos às situações da vida; atividades para crianças que aprendem mais depressa ou mais devagar; recursos e atividades para fixação de noções, já desenvolvidas; recursos para avaliação do progresso do aluno (COLTED, 1970, p. 132).

Essas recomendações demonstram que a Colted concebia o livro como um recurso que contribui para a formação dos professores primários, já que ele fornece saberes para ensinar matemática, objetivando propor um ensino inovador e que considera o aluno um ser ativo no seu próprio processo de ensino e aprendizagem. Vemos, ainda, que, ao propor atividades diferenciadas para alunos que aprendem mais rápido e mais lentamente, ela revela uma preocupação em atender particularidades dos alunos, ou seja, demonstra estar atenta à inclusão de alunos com tempos de aprendizagem diferenciados.

Quanto à utilização de livros didáticos, a Colted informou que alguns livros, devido à sua estrutura, sugerem um determinado tipo de trabalho, no entanto, há diversas formas de se utilizar um livro. Ele pode ser usado para introduzir um assunto, no meio do desenvolvimento de uma atividade, sob orientação direta do professor ou após ter sido desenvolvida uma noção matemática, servindo assim para sistematizar e enriquecer a aprendizagem. Veremos a seguir um exemplo de atividade que utiliza o livro para introduzir um assunto. 


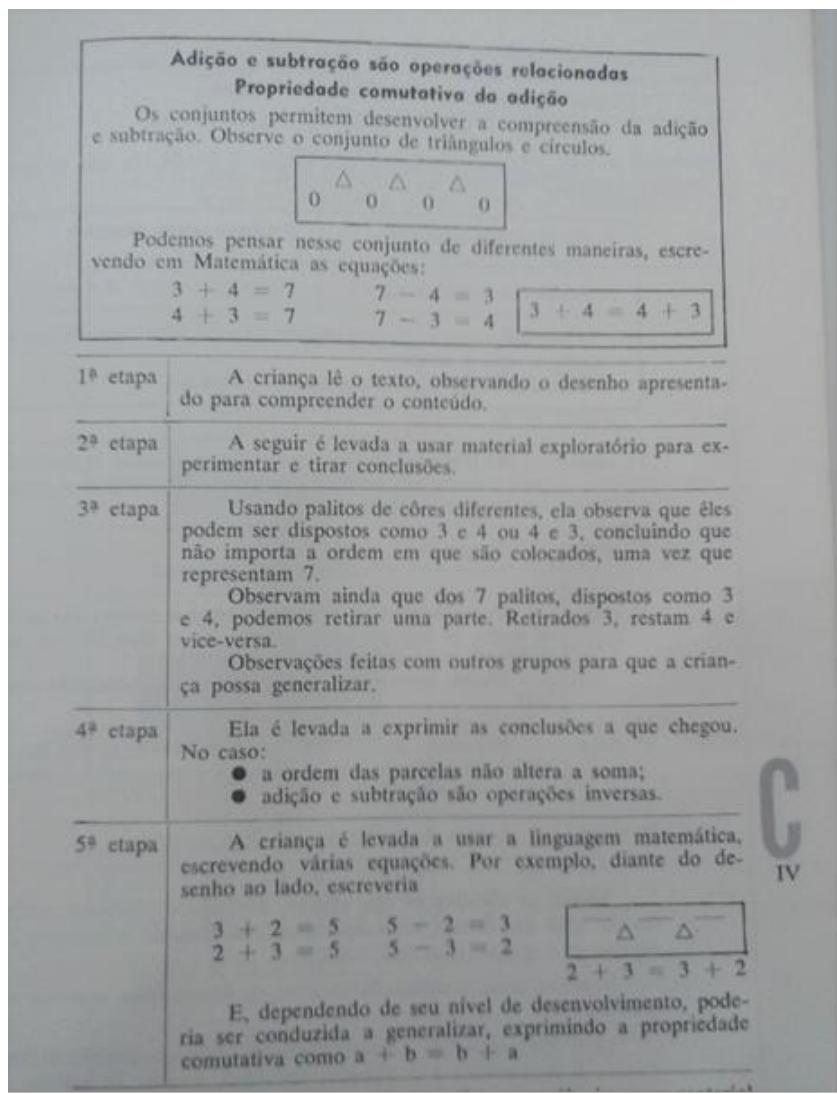

Figura 2 - Sugestão de atividade.

Fonte: COLTED (1970, p. 133).

Percebemos na atividade explicitada na imagem, assim como em outros exemplos do manual, que a Colted buscava valorizar o método da descoberta, por considerar que tal método incentivava a utilização do livro e favorecia a aprendizagem do aluno. Segundo Dantas (1987), o ensino que se baseia no processo de exposição não prepara o aluno para estudar sozinho e, assim, o livro que deveria ser utilizado como um instrumento de trabalho do aluno acaba se tornando uma peça de museu. Isso não ocorre no processo de descoberta, já que o aluno é colocado em situações que o incentivam a descobrir conceitos, regras e princípios e, considerando que nem sempre os alunos podem descobrir tudo por eles mesmos, por vezes, faz-se necessário um direcionamento. É aí então, nesse contexto, que a utilização de livros, se torna uma estratégia heurística, ou seja, serve para guiar as atividades de investigação.

\section{Considerações finais}

A institucionalização das Escolas Normais no Brasil ocorreu em virtude da necessidade de capacitar professores para o ensino primário, já que este nível de escolaridade passou a ser considerado indispensável para a população do País, após a proclamação da 
independência. Essa preocupação com a formação docente se manifestou também em livros e manuais didáticos, os quais buscavam orientar os docentes no processo de ensino e aprendizagem.

Por reconhecer a importância do livro didático para a melhoria da qualidade do ensino, devido a sua influência na política de educação e de desenvolvimento econômico e social do Brasil e diante da necessidade de ofertar livros adequados para os alunos, o Brasil criou a Colted. Dentre as principais ações realizadas por essa Comissão destacamos a distribuição de livros didáticos e técnicos destinados a orientar os professores no ensino de diversas disciplinas e de livros informativos e livros didáticos para alunos e o oferecimento de cursos de treinamento para professores, no intuito de capacitá-los para o uso de livros e direcionálos no processo de escolha dos livros didáticos.

O manual intitulado O livro didático: sua utilização em classe, analisado neste artigo, foi publicado pela Colted, em sua segunda edição, em 1970. Ele apresenta, inicialmente, uma abordagem sobre o ensino primário na época, destacando os desafios que este nível de escolaridade enfrentava; conceitua o livro didático e seus objetivos; e faz recomendações sobre como avaliar e como utilizar o livro didático. Após essa primeira parte, denominada de princípios gerais, o citado livro traz orientações para as disciplinas específicas, dentre elas a matemática. A unidade $\mathrm{C}$, que trata especificamente da matemática, não só aborda sobre o porquê ensinar matemática e como ensiná-la, como orienta avaliar e usar o livro de matemática.

Nessa análise buscamos interpretar de que forma os saberes relacionados ao ensino de matemática, ali abordados, estiveram presentes na formação das discentes do Curso Normal do IERP, no final da década de 1960 e início da década de 1970. Percebemos pelas falas das depoentes Jacy Andrade Sturken - estudante do Curso Normal do IERP no período de 1969 a 1971 - e Nina Rosa Braga Cardoso - normalista do IERP no período de 1970 a 1972 que os conteúdos específicos de matemática descritos no manual - saberes a ensinar matemática - são aqueles destinados ao primário e ali seriam ministrados.

Já no que diz respeito aos saberes para ensinar, foi possível identificar, no manual, a presença significativa de orientações de como ensinar matemática, presentes também na formação das normalistas do Curso Normal do IERP, contudo algumas peculiaridades na 
apropriação de determinadas ideias nos chamaram a atenção, por exemplo, em relação ao objetivo social da matemática, o qual indicava que a criança deve compreender a importância da matemática em sua vida. No Curso Normal do IERP houve uma apropriação desse objetivo, ao oportunizarem que os alunos visitassem um mercadinho e vissem "[...] que a anotação era feita na caderneta, com a venda a prazo [...]".

Isso nos remete a Chartier (2002), quando afirma que as apropriações não ocorrem de forma neutra, são influenciadas pelos contextos em que as pessoas estão inseridas. Esse autor pontua ainda que, desse modo, devemos compreender as práticas de apropriação cultural como formas diferenciadas de interpretação, em um contexto que emergem consensos, discordâncias, conflitos e diferenças organizadas por estratégias de distinção ou imitação.

Para além dos saberes relacionados ao ensino de matemática, apontados ao longo do texto, abordados nas disciplinas de Matemática, Estatística, Matemática e Estatística, Desenho Aplicado, Didática Geral e Didática Especial, ambas as depoentes destacam a importância dada pelo curso a conhecimentos da área de Psicologia, os quais também constituíam o conjunto de saberes para ensinar abordados no citado curso. Percebemos que houve mudanças na grade de disciplinas do Curso Normal do IERP, no período em que as citadas discentes ali estudaram, as quais podem ser explicadas, se levarmos em conta os aspectos levantados por Chervel (1990) em relação à história das disciplinas, conforme relatamos no texto. É pertinente destacar que os modos de ensinar, ou seja, os saberes para ensinar, presentes no manual $O$ livro didático: sua utilização em classe e nos depoimentos revelam indícios da proposta da Escola Nova e do Movimento da Matemática Moderna.

\section{Referências}

BATISTA, Carmyra Oliveira; SANTOS, Edilene Simões Costa dos; SOUZA, Mônica Menezes de. A Comissão do Livro Técnico e do Livro Didático (COLTED) e o treinamento de professores para o uso do livro didático. In: ENCONTRO NACIONAL DE PESQUISA EM HISTÓRIA DA EDUCAÇÃO MATEMÁTICA, 3., São Mateus, ES. Anais [...] São Mateus: SBHMat, 2016. p. 1025-1036.

BRAGA, Maria Nilza Silva; DIAS, André Luiz Mattedi. Contribuições dos cursos oferecidos pelo Programa de Treinamento e Aperfeiçoamento de Professores de Ciências Experimentais e Matemática-PROTAP na formação dos professores de matemática da educação básica de Jequié-Bahia para lidar com o novo currículo matemático na década de 70. In: ENCONTRO NACIONAL DE EDUCAÇÃO MATEMÁTICA, 10., Salvador, 2010. Anais [...] Salvador, 2010, p. 1- 
10. Disponível em: http://www.lematec.net.br/CDS/ENEM10/artigos/CC/T13_CC742.pdf. Acesso: 12 jan. 2018.

BRASIL. Decreto no 59.355, de 4 de outubro de 1966. Institui no Ministério da Educação e Cultura a Comissão do Livro Técnico e do Livro Didático (COLTED) e revoga o Decreto número 58.653-66. Disponível em: http://www2.camara.leg.br/legin/fed/decret/19601969/decreto-59355-4-outubro-1966-400010-publicacaooriginal-1-pe.html. Acesso em: 08 nov. 2018.

CARDOSO, Nina Rosa Braga. Entrevista [30 nov. 2017]. Entrevistadora: Cleide Selma Pereira dos Santos (Arquivo particular). Entrevista gravada no dia 30 de novembro de 2017, em Jequié-BA, para a pesquisa de Mestrado do PPG-ECFP da UESB.

CHARTIER, Roger. História cultural: entre práticas e representações. Tradução Maria Manoela Galhardo. 2. ed. Lisboa: Difel, 2002.

CHERVEL, André. História das disciplinas escolares: reflexões sobre um campo de pesquisa.

Teoria \& Educação, Porto Alegre, n. 2, p. 177-229, 1990. Disponível em:

http://moodle.fct.unl.pt/pluginfile.php/122510/mod_resource/content/0/Leituras/Chervel0 1.pdf. Acesso em: 08 maio 2016.

COLTED. O livro didático: sua utilização em classe. 2. ed. rev. e atual. [s.I.]: MEC, 1970.

DANTAS, Martha Maria de Souza. Ensino de matemática: um processo entre a exposição e a descoberta. Salvador: Centro Editorial e Didático da UFBA, 1987.

FARIAS, Magnólia Santana de. Entrevista [15 jun. 2017]. Entrevistadora: Cleide Selma Pereira dos Santos (Arquivo particular). Entrevista gravada no dia 15 de junho de 2017, em JequiéBA, para a pesquisa de Mestrado do PPG-ECFP da UESB.

FILGUEIRAS, Juliana Miranda. As políticas para o livro didático durante a ditadura militar: a COLTED e a FENAME. Hist. Educ. (Online), Porto Alegre, v. 19, n. 45, p. 85-102, jan./abr., 2015.

HOFSTETTER, Rita; SCHNEUWLY Bernard. Saberes: um tema central para as profissões do ensino e da formação. In: HOFSTETTER, Rita; VALENTE, Wagner Rodrigues. Saberes em transformação: tema central da formação de professores. São Paulo: Livraria da Física, 2017a. p. 113-172.

HOFSTETTER, Rita; SCHNEUWLY Bernard. Disciplinarização e disciplinação: as ciências da educação e as didáticas das disciplinas sob análise. In: HOFSTETTER, Rita; VALENTE, Wagner Rodrigues. Saberes em transformação: tema central da formação de professores. São Paulo: Livraria da Física, 2017b. p. 21-54.

MEIHY, José Carlos Sebe Bom. Manual de história oral. 3. ed. São Paulo: Edições Loyola, 1996.

MOREIRA, Antônio Flávio Barbosa. Currículos e Programas no Brasil. 18. ed. Campinas: Papirus, 2012.

MATTOS, Luiz Alves de. Sumário de Didática Geral. 8. ed. Rio de Janeiro: Editora Aurora, 1968. 
PINTASSILGO, Joaquim; PEDRO, Lénia Cristina. A disciplina de Didáctica Especial na escola do magistério primário de Lisboa. O exemplo do prof. Moreirinhas Pinheiro. Disponível em: http://repositorio.ul.pt/bitstream/10451/10738/1/A\%20disciplina\%20de\%20Did\%C3\%A1tica \%20Especial.pdf. Acesso: 12 out. 2017.

SANTOS, Cleide Selma Pereira dos. História da formação docente no curso normal do Instituto de Educação Régis Pacheco (1959-1971): o ensino da matemática em foco. 2018. 218 f. Dissertação (Mestrado em Educação Científica e Formação de Professores) Departamento de Ciências Biológicas, Universidade Estadual do Sudoeste da Bahia, Jequié, 2018.

SOUZA, lone Celeste de; CRUZ, Antônio Roberto Seixas da. Escolas Normais da Bahia: olhares e abordagens. Feira de Santana: UEFS Editora, 2012.

STURKEN, Jacy Andrade. Entrevista [27 mar. 2017]. Entrevistadora: Cleide Selma Pereira dos Santos (Arquivo particular). Entrevista gravada no dia 27 de março de 2017, em Jequié-BA, para a pesquisa de Mestrado do PPG-ECFP da UESB.

TANURI, Leonor Maria. História da formação de professores. Revista Brasileira de Educação, Rio de Janeiro, ANPED, n. 14, p. 61-88, maio/ago, 2000.

VIDAL, Diana Gonçalves. Escola Nova e processo educativo. In: LOPES, Eliana Marta Teixeira; FARIA FILHO, Luciano Mendes de; VEIGA, Cynthia Greive. 500 anos de educação no Brasil. 4. ed. Belo Horizonte: Autêntica, 2010. p. 497-517.

Recebido em: 21/11/2018

Aprovado em: 25/06/2019 